Original article

\title{
A survey of psychological distress among Bangladeshi people during the COVID-19 pandemic
}

\author{
Roy Rillera Marzo ${ }^{\mathrm{a}, *}$, Akansha Singh ${ }^{\mathrm{b}}$, Roushney Fatima Mukti ${ }^{\mathrm{c}}$ \\ ${ }^{\text {a }}$ Asia Metropolitan University, Malaysia \\ ${ }^{\mathrm{b}}$ Durham University, United Kingdom \\ ${ }^{\mathrm{c}}$ Department of Genetic Engineering \& Biotechnology, East West University, Bangladesh
}

\section{A R T I C L E I N F O}

\section{Keywords:}

Psychological distress

Peritraumatic distress index

COVID-19

\begin{abstract}
A B S T R A C T
Introduction: Previous studies conducted on the psychological impact of infectious outbreaks have found heavy psychological burdens among general population with more severe affect in the current pandemic. The main aim of this study is to examine the level of psychological distress during COVID-19 in Bangladesh and explore factors associated with higher psychological distress.

Methods: An internet-based, cross-sectional survey was conducted from March to April 2020 in Bangladesh among adults 18 years old and above using structured online questionnaires distributed through emails and other social media throughout Bangladesh with an overall response rate of 34\%. Modified version of the Covid19 peritraumatic distress index (CPDI) was used to measure distress. Univariate and Bivariate analysis was used to estimate prevalence of CPDI symptoms and test for the associations between CPDI and the exposure variables. Logistic regression analyses were used to estimate the odds ratios of our outcome variable by exposure variables. Results: Overall, $44.3 \%$ of respondents were suffering from mild to moderate distress and $9.5 \%$ were suffering from severe distress. Female respondents were 2.435 times more likely to suffer from CPDI mild to severe distress than males. As compared to Dhaka and Mymensing region of Bangladesh, odds of distress was 1.945 times more in Chittagong/Sylhet region (p-value $=0.035$ ).

Conclusion: Large proportion of adult population in Bangladesh are experiencing psychological distress, with level of distress varies by different symptoms and predictors. This study suggest the need to develop comprehensive crisis prevention system including epidemiological monitoring, screening, and referral with targeted intervention to reduce psychological distress.
\end{abstract}

\section{Introduction}

The corona virus disease 2019 (COVID-19) outbreak is posing a serious public health threat worldwide. The virus has been named severe acute respiratory syndrome coronavirus 2 (SARS-CoV-2). In this report, we will refer to the disease, COVID-19.According to the World Health Organization (WHO), as of 22 July 2020, 14,562,550 confirmed cases and 607,781 deaths have been reported globally. ${ }^{1}$ In Bangladesh, from Mar 8 to 21 July 2020, there have been 207,453 confirmed cases of COVID-19 with 2668 deaths. $^{2}$

The epidemic has had a strong impact on general population's daily life. At the same time, as the epidemic continues, general population gradually experience different levels of psychological distress, such as nervousness, fear of infection, anxiety, depression, sleep problems, and inattention. Studies conducted on the psychological impact of previous infectious outbreaks, such as the severe acute respiratory syndrome (SARS) that is similar to the COVID-19 pandemic, have found heavy psychological burdens among healthcare workers and the general public such as anxiety, depression, panic attacks, or psychotic symptoms. ${ }^{3,4}$ Other studies have reported that some psychological problems often occur during similar epidemic ${ }^{5,6}$ or other traumatic stress events, such as natural disasters, ${ }^{7,8}$ disease, ${ }^{9}$ or long-term employment in high stress occupations, ${ }^{10-12}$ and may last for a long time. ${ }^{13,14}$

Since the case number of COVID-19 is still rapidly increasing in many countries particularly in Bangladesh, psychological disturbances may have impacted and will continue to impact millions of people around the world. Understanding the psychological impact would provide theoretical basis for the identification of high-risk people and designing

\footnotetext{
* Corresponding author.

E-mail addresses: rrmtexas@yahoo.com (R.R. Marzo), akansha.singh@durham.ac.uk (A. Singh), roushney@ewubd.edu (R.F. Mukti).
} 
interventions, as well as planning resources and promulgating national and governmental policies, which is of critical importance and public health implication at a global level.

The aims of this study are to evaluate the level of psychological distress during COVID-19 and to explore factors associated with higher psychological distress.

\section{Methods}

\subsection{Study setting and population}

An internet-based cross-sectional survey was conducted from March to April 2020 during the movement restriction took place. Snowball sampling, a type of convenience sampling method was used for the data collection using research networks of universities, hospitals, friends and their relatives. The criteria of selecting the participants was that only those adults who were 18 years old and above and resides in Bangladesh for a minimum of one week during the COVID-19 pandemic announcement made by the WHO were considered. The structured online questionnaires were conveniently distributed through emails, WhatsApp, Telegram, and other social media throughout this network in Bangladesh.

\subsection{Process of data collection}

Data collection started 2 weeks after the announcement by the WHO that COVID-19 was pandemic. The online link was available for about 1 month. Our study was an online survey which was completely voluntary. The consented participants were able to respond only once using a single account by setting the feature to prevent more than one response from the same history. The participants were asked to give a response based on their previous one week experience. Spreadsheets responses were exported into IBM SPSS version 25 for further analaysis. Overall response rate of the survey was $34 \%$.

\subsection{Study tool (measurement)}

Data were collected using a structured online questionnaire. The questionnaire has two parts; Part 1 - Sociodemographic data (state, gender, age, education, marital status, co-morbidities), Part 2 - COVID19 Peritraumatic Distress Index (CPDI), which was developed by Qiu, Shen et al. ${ }^{15}$ The COVID-19 CPDI was a self-reported questionnaire, which has 24 questions using Likert Scale (never, occasionally, sometimes, often and always) of anxiety, depression, specific phobias, cognitive change, avoidance, and compulsive behavior, physical symptoms and loss of social functioning in the past week. The questionnaire incorporated relevant diagnostic guidelines for specific phobias and stress disorders specified in the International Classification of Diseases, 11th revision, and expert opinions from psychiatrists and psychologists. The total score ranging from 0 to 100 . A score between 28 and 51 indicates mild to moderate distress. A score of $\geq 52$ indicates severe distress. ${ }^{15}$ CPDI was translated into Bengali. Pilot testing with 30 participants to test the face validity and internal consistency. The Cronbach's alpha of 0.812 indicated that the questionnarie has an excellent internal consistency.

\subsection{Statistical methods}

Exposure variable: The exposure variables included socio-economic and demographic variables such as age (18-30 years,30+), gender (male, female), Education (school, college), employment (employed, not-employed, students), Income in Bangladeshi Taka (BDT) (BDT less than 25,000, BDT 25,000 to less than 50,000, BDT More than 50,000), religion (Islam, Others (include Buddhism, Christianity, Hindu and other)), region (Dhaka/Mymensing, Rajshahi/Rangpur, Barisal/Khulna, Chittagong/Sylhet).
Outcome Variable: Modified version of the Covid19 peri-traumatic distress index(CPDI) with 24 items was used. The present study has used the Bangla version of the CPDI, and internal consistency was assessed by using Cronbach's $\alpha$. The internal reliability of the index was found to be 0.875 . For each of the 24 items, subjects were asked to measure emotional impact related to COVID-19 and their frequency of the activities in the last week. The 5-point Likert scoring system was used as follows: Never-0, Occasionally-1, Sometimes-2, Often-3, Always -4. A total of the score of $0-28$ is normal. A total score between 29 and 51 indicates mild to moderate distress and a score of greater than and equal to 52 indicates severe distress. Further, this category of three was modified in two categories one is normal or no distress and the other one is mild to moderate and severe distress as distressed.

Statistical Analysis: Univariate analysis was conducted to assess the percentage of Covid19 peri-traumatic distress index (CPDI) by socioeconomic, demographic and regional variables. A Chi-square test was used to test for the associations between CPDI and the exposure variables, as this test is suitable to test the association for two categorical variables. Logistic regression analyses was used to estimate the odds ratios of our dichotomous outcome variable by exposure variables. Outcome variable CPDI normal is coded as 0 and mild to moderate or severe distress was recoded as 1 . The exposure variables were categorical in nature.

\section{Results}

Overall, data for 503 respondents was used for the statistical analysis. Table 1 shows percentage of each symptom of Covid19 peritraumatic distress index based on their frequency. The prevalence of most of the symptoms decreases linearly from the maximum prevalence in never category to minimum in always category except S5, S3 and S6. However, there is huge variation in the prevalence across symptoms for any specific category. For example, respondents who reported always suffering from these symptom varies from $0.8 \%$ (S22) to $78.1 \%$ (S5). Similarly respondents who reported often suffering from these symptoms varies from $2.8 \%$ (S10) to $25.0 \%$ (S6).

The CPDI items and their mean and standard deviation (SD) are presented in Table 2. The item means ranged from the minimum 0.3 (for S9 and S22) to the maximum 3.7 (for S5). The mean total score was 31.5 \pm 14.0 . The reliability of this index is very high as evident from the Cronbach Alpha estimates.

Fig. 1 shows the prevalence of normal, mild to moderate and sever distress of Covid19. Overall, $44.3 \%$ of respondents were suffering from mild to moderate distress and $9.5 \%$ were suffering from severe distress in Bangladesh. Table 3 shows the prevalence of CPDI by socioeconomic and demographic characteristics in Bangladesh. Prevalence of mild to moderate and severe distress was higher among females than males. The prevalence of mild to moderate distress among males was $41.2 \%$ and $48.6 \%$ among females and the severe distress prevalence was $4.1 \%$ among males and $17.0 \%$ among females.Similar stark differences in the prevalence was observed for employment, household income and regional categories. For example, prevalence of mild to moderate distress and severe distress was much higher in Barisal/Khulna (mild to moderate distress 52.9\%; severe distress $8.8 \%$ ) and Chittagong/Sylhet (mild to moderate distress $53.7 \%$; severe distress $11.1 \%$ ) region of Bangladesh than other regions (Table 3). Further, prevalence of mild distress was higher among respondents from other religion, with 30+ years of age and those who are educated to college level than their counterparts. On the other hand, prevalence of severe distress was much higher among respondents with 18-30 years of age, belonging to Islamic community and school education.

Results of the logistic regression analysis are summarised in Table 4. Mild to moderate and severe distress was coded as ' 1 ' while Normal distress level was coded as ' 0 '. Gender was significantly associated with distress (OR $=2.435,95 \%$ CI 1.662 to 3.568 ). Female respondents were 2.435 times more likely to suffer from CPDI mild to severe distress than 
Table 1

Presence of Covid19 peri-traumatic distress index (CPDI), Bangladesh.

\begin{tabular}{|c|c|c|c|c|c|}
\hline Symptoms & $\begin{array}{l}\text { Never } \mathrm{n}, \\
(\%)\end{array}$ & $\begin{array}{l}\text { Occasionally } \mathrm{n}, \\
(\%)\end{array}$ & $\begin{array}{l}\text { Sometimes } \mathrm{n} \text {, } \\
(\%)\end{array}$ & $\begin{array}{l}\text { Often n, } \\
(\%)\end{array}$ & $\begin{array}{l}\text { Always } \mathrm{n}, \\
(\%)\end{array}$ \\
\hline S1 & $35(7.0)$ & $76(15.1)$ & $215(42.7)$ & $\begin{array}{l}111 \\
(22.1)\end{array}$ & $66(13.1)$ \\
\hline S2 & $\begin{array}{l}263 \\
(52.3)\end{array}$ & $107(21.3)$ & $77(15.3)$ & $40(8.0)$ & $16(3.2)$ \\
\hline S3 & $39(7.8)$ & $103(20.5)$ & $150(29.8)$ & $\begin{array}{l}116 \\
(23.1)\end{array}$ & 95(18.9) \\
\hline S4 & $\begin{array}{l}148 \\
(29.4)\end{array}$ & $101(20.1)$ & $129(25.6)$ & $\begin{array}{l}78 \\
(15.5)\end{array}$ & $47(9.3)$ \\
\hline S5 & $5(1.0)$ & $10(2.0)$ & $28(5.6)$ & $\begin{array}{l}67 \\
(13.3)\end{array}$ & $\begin{array}{l}393 \\
(78.1)\end{array}$ \\
\hline S6 & $\begin{array}{l}59 \\
(11.7)\end{array}$ & $91(18.1)$ & $148(29.4)$ & $\begin{array}{l}126 \\
(25.0)\end{array}$ & 79(15.7) \\
\hline S7 & $\begin{array}{l}144 \\
(28.6)\end{array}$ & $114(22.7)$ & $113(22.5)$ & $\begin{array}{l}89 \\
(17.7)\end{array}$ & $43(8.5)$ \\
\hline S8 & $\begin{array}{l}138 \\
(27.4)\end{array}$ & $118(23.5)$ & 105(20.9) & $\begin{array}{l}70 \\
(13.9)\end{array}$ & $72(14.3)$ \\
\hline S9 & $\begin{array}{l}433 \\
(86.1)\end{array}$ & $33(6.6)$ & $14(2.8)$ & $12(2.4)$ & $11(2.2)$ \\
\hline S10 & $\begin{array}{l}373 \\
(74.2)\end{array}$ & $52(10.3)$ & $46(9.1)$ & $14(2.8)$ & $18(3.6)$ \\
\hline S11 & $\begin{array}{l}340 \\
(67.6)\end{array}$ & $75(14.9)$ & $50(9.9)$ & $28(5.6)$ & $10(2.0)$ \\
\hline S12 & $\begin{array}{l}252 \\
(50.1)\end{array}$ & 95(18.9) & 100(19.9) & $40(8.0)$ & $16(3.2)$ \\
\hline S13 & $\begin{array}{l}213 \\
(42.3)\end{array}$ & $126(25.0)$ & $93(18.5)$ & $\begin{array}{l}52 \\
(10.3)\end{array}$ & $19(3.8)$ \\
\hline S14 & $\begin{array}{l}105 \\
(20.9)\end{array}$ & $121(24.1)$ & $130(25.8)$ & $\begin{array}{l}97 \\
(19.3)\end{array}$ & $50(9.9)$ \\
\hline S15 & $\begin{array}{l}122 \\
(24.3)\end{array}$ & $118(23.5)$ & $126(25.0)$ & $\begin{array}{l}107 \\
(21.3)\end{array}$ & $30(6.0)$ \\
\hline S16 & $\begin{array}{l}118 \\
(23.5)\end{array}$ & $118(23.5)$ & $123(24.5)$ & $\begin{array}{l}107 \\
(21.3)\end{array}$ & $37(7.4)$ \\
\hline S17 & $\begin{array}{l}158 \\
(31.4)\end{array}$ & $125(24.9)$ & $118(23.5)$ & $\begin{array}{l}71 \\
(14.1)\end{array}$ & $31(6.2)$ \\
\hline S18 & $\begin{array}{l}269 \\
(53.5)\end{array}$ & 99(19.7) & $73(14.5)$ & $\begin{array}{l}53 \\
(10.5)\end{array}$ & $9(1.8)$ \\
\hline S19 & $\begin{array}{l}275 \\
(54.7)\end{array}$ & 119(23.7) & 69(13.7) & $31(6.2)$ & $9(1.8)$ \\
\hline S20 & $\begin{array}{l}259 \\
(51.5)\end{array}$ & $96(19.1)$ & 79(15.7) & $46(9.1)$ & $23(4.6)$ \\
\hline S21 & $\begin{array}{l}281 \\
(55.9)\end{array}$ & $84(16.7)$ & $65(12.9)$ & $\begin{array}{l}51 \\
(10.1)\end{array}$ & $22(4.4)$ \\
\hline S22 & $\begin{array}{l}403 \\
(80.1)\end{array}$ & $52(10.3)$ & $26(5.2)$ & $18(3.6)$ & $4(0.8)$ \\
\hline S23 & $\begin{array}{l}164 \\
(32.6)\end{array}$ & $130(25.8)$ & 91(18.1) & $\begin{array}{l}76 \\
(15.1)\end{array}$ & $42(8.3)$ \\
\hline S24 & $\begin{array}{l}344 \\
(68.4)\end{array}$ & $77(15.3)$ & $37(7.4)$ & $29(5.8)$ & $16(3.2)$ \\
\hline
\end{tabular}

males. Respondents with $30+$ years of age have $3 \%$ lower odds to suffer from CPDI mild to severe distress than those who are 18-30 years of age. The estimated odds of distress was 1.016 times (95\% CI 0.596 to 1.732) for respondents with college education as compared to school education. As compared to Dhaka/Mymensing, odds of distress was 1.436 times for respondents from Barisal/Khulna and the odds of distress was 1.945 times and significant in Chittagong/Sylhet (p-value $=0.035$ ). By employment status, employed respondents were 1.772 times and students were 1.260 times more likely to suffer from mild to severe distress than unemployed respondents. The effect of household income on distress was not significant.

\section{Discussion}

The Coronavirus Disease 2019 (COVID-19) epidemic emerged in Wuhan, China, spread nationwide and then onto several other counties in the world between December 2019 and early 2020. The virus was confirmed to have started spreading to Bangladesh in March 2020. In response to COVID-19 increasing cases, Bangladesh declared a 10-day shutdown effective from 26 March to 4 April, ${ }^{16}$ which was later
Table 2

Descriptive statistics and internal consistency of OVID19 Peri-traumatic distress index (CPDI), Bangladesh.

\begin{tabular}{lllll}
\hline Symptoms & Mean & SD & $\begin{array}{l}\text { Corrected Item-Total } \\
\text { Correlation }\end{array}$ & $\begin{array}{l}\text { Cronbach's Alpha if Item } \\
\text { Deleted }\end{array}$ \\
\hline S1 & 2.2 & 1.1 & .509 & .869 \\
S2 & 0.9 & 1.1 & .283 & .875 \\
S3 & 2.2 & 1.2 & .438 & .871 \\
S4 & 1.6 & 1.3 & .654 & .863 \\
S5 & 3.7 & 0.8 & .047 & .879 \\
S6 & 2.1 & 1.2 & .396 & .872 \\
S7 & 1.5 & 1.3 & .398 & .872 \\
S8 & 1.6 & 1.4 & .315 & .875 \\
S9 & 0.3 & 0.8 & .192 & .876 \\
S10 & 0.5 & 1.0 & .228 & .876 \\
S11 & 0.6 & 1.0 & .281 & .875 \\
S12 & 1.0 & 1.1 & .273 & .875 \\
S13 & 1.1 & 1.2 & .558 & .867 \\
S14 & 1.7 & 1.3 & .681 & .863 \\
S15 & 1.6 & 1.2 & .683 & .863 \\
S16 & 1.7 & 1.3 & .664 & .863 \\
S17 & 1.4 & 1.2 & .650 & .864 \\
S18 & 0.9 & 1.1 & .528 & .868 \\
S19 & 0.8 & 1.0 & .503 & .869 \\
S20 & 1.0 & 1.2 & .531 & .868 \\
S21 & 0.9 & 1.2 & .493 & .869 \\
S22 & 0.3 & 0.8 & .381 & .872 \\
S23 & 1.4 & 1.3 & .397 & .872 \\
S24 & 0.6 & 1.1 & .414 & .871 \\
Overall & 31.5 & 14.0 & & \\
\hline & & & & .875 \\
\hline
\end{tabular}

increased.The implementation of unprecedented strict quarantine measures in all countries including Bangladesh, has kept a large number of people in isolation and affected many aspects of people's lives. It has also triggered a wide variety of psychological problems, such as panic disorder, anxiety and depression which needs to be measured. This study aims to measure psychological distress levels among adultsin Bangladesh, where 207,453coronavirus confirmed cases was observed until 21st July2020. Peritraumatic distress is defined as the emotional and physiological distress experienced during and/or immediately after a traumatic event (COVID 19 in our case) and is associated with the development and severity of posttraumatic stress disorder (PTSD) and related psychological difficulties. ${ }^{17}$ The Peritraumatic Distress Index (PDI) is a widely-used self-report measure.The reliability of this index is very high in this study as it is evident from the Cronbach Alpha estimates. COVID-19 Peri-traumatic distress index (CPDI) has also been used in other countries to measure psychological distress in Peru, Iran ${ }^{18}$ and China. ${ }^{15}$

Covid-19 is expected to effect the mental health of the public as it is evidenced from other traumatic events in other countries. The prevalence of such distress is expected to be much higher in low and middle countries. ${ }^{19}$ The adults in this study have reported a mean distress level total score of 31.5 with s.d.14.0. The distress level of Bangladesh adults is much higher than Chinese adults (mean: 23.65; s.d.: 5.45) but slightly lower than Iranian adults (mean: 34.54; s.d.: 14.92) as reported in a prior study ${ }^{18}$ with the same measure of Covid-19 Peritraumatic Distress Index (CPDI).There is significant variation in the prevalence across 24 symptoms of this index, but overall more than half of the adults in this survey have reported to suffer mild to severe distress.

Female respondents in Bangladesh have shown significantly higher CPDI than their male counterparts. It is in accordance with results from previous research of COVID-19 inChina which concluded that women are much more vulnerable to stress and more likely to develop posttraumatic stress disorder. ${ }^{15}$ Being female is one of the strong risk factors for mental health problems. ${ }^{20} \mathrm{UN}$ Women Regional Office for Asia and the Pacific (ROAP) has conducted a survey in several countries in the region including Bangladesh and suggest that COVID-19 will have gendered effects in this region. As the pandemic continues to evolve at a different pace across the Asia-Pacific region, it will be essential to 


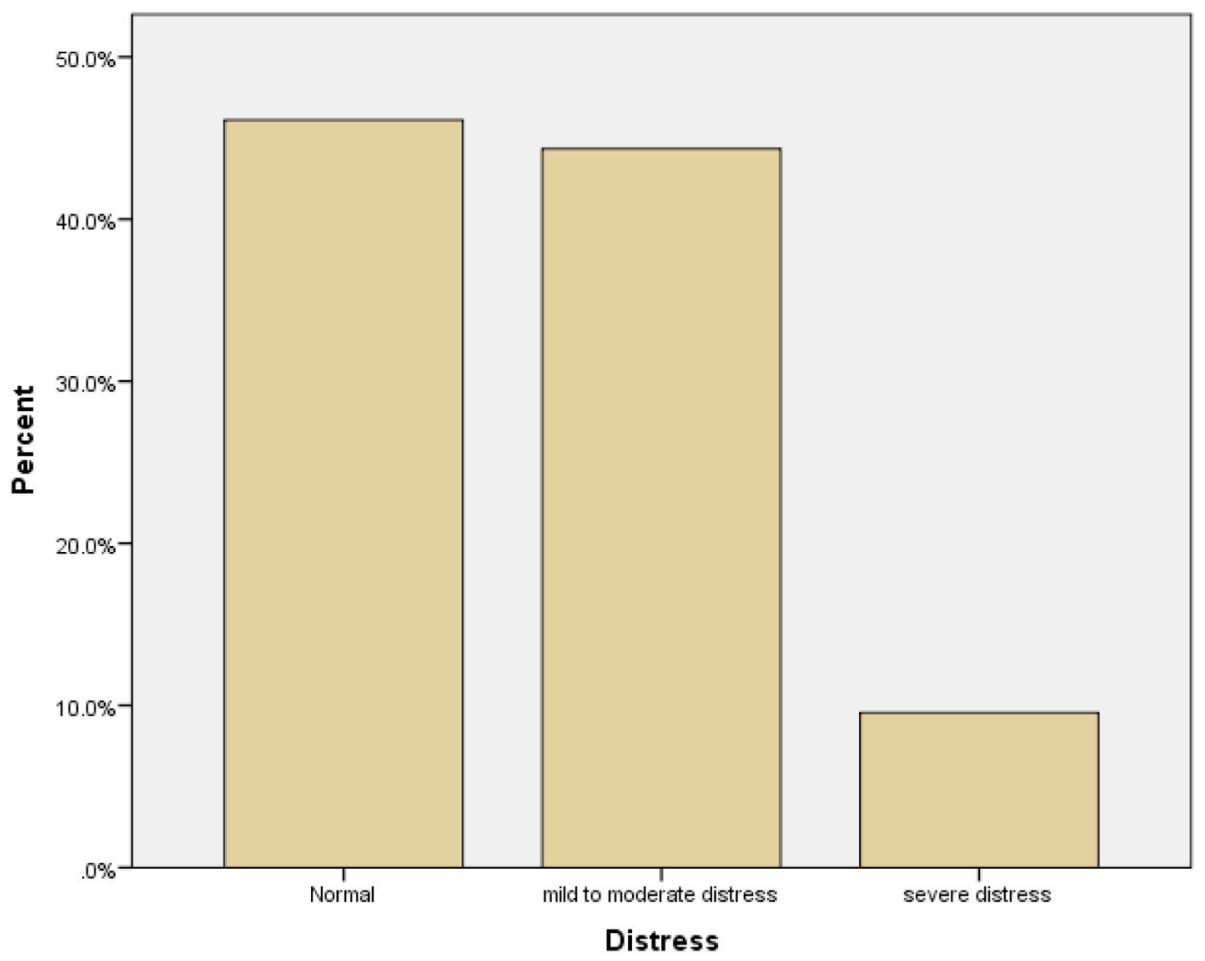

Fig. 1. Prevalence of physiological distress in COVID-19, Bangladesh.

Table 3

Prevalence of CPDI by socioeconomic and demographic characteristics, Bangladesh.

\begin{tabular}{|c|c|c|c|c|c|c|c|}
\hline & & Normal & mild to moderate distress & severe distress & Sample size & Chi-square test & P-value \\
\hline Overall & & 46.1 & 44.3 & 9.5 & 503 & & \\
\hline \multirow[t]{2}{*}{ Gender } & Male & 54.6 & 41.2 & 4.1 & 291 & 33.596 & 0.000 \\
\hline & Female & 34.4 & 48.6 & 17.0 & 212 & & \\
\hline \multirow[t]{2}{*}{ Religion } & Others & 44.9 & 53.1 & 2.0 & 49 & 4.152 & 0.125 \\
\hline & Islam & 46.3 & 43.4 & 10.4 & 454 & & \\
\hline \multirow[t]{2}{*}{ Age } & 18-30 year & 46.5 & 43.8 & 9.6 & 447 & .385 & 0.825 \\
\hline & $30+$ years & 42.9 & 48.2 & 8.9 & 56 & & \\
\hline \multirow[t]{2}{*}{ Education } & School & 45.8 & 38.9 & 15.3 & 72 & 3.460 & 0.177 \\
\hline & College & 46.2 & 45.2 & 8.6 & 431 & & \\
\hline \multirow[t]{3}{*}{ Employment } & Not Employed & 52.7 & 40.7 & 6.6 & 91 & 3.057 & 0.548 \\
\hline & Employed & 41.9 & 47.1 & 11.0 & 136 & & \\
\hline & Student & 46.0 & 44.2 & 9.8 & 276 & & \\
\hline \multirow[t]{3}{*}{ House Income } & BDT less than 25,000 & 49.6 & 41.9 & 8.5 & 129 & 1.162 & 0.884 \\
\hline & BDT 25,000 to less than 50,000 & 44.7 & 46.0 & 9.3 & 215 & & \\
\hline & BDT More than 50,000 & 45.3 & 44.0 & 10.7 & 159 & & \\
\hline \multirow[t]{4}{*}{ Region } & Dhaka/Mymensing & 47.2 & 42.9 & 10.0 & 371 & 6.562 & 0.363 \\
\hline & Rajshahi/Rangpur & 56.8 & 38.6 & 4.5 & 44 & & \\
\hline & Barisal/Khulna & 38.2 & 52.9 & 8.8 & 34 & & \\
\hline & Chittagong/Sylhet & 35.2 & 53.7 & 11.1 & 54 & & \\
\hline
\end{tabular}

monitor the gender differences in health risks, household responsibilities and job vulnerability. ${ }^{21}$ Significant regional variations has also been observed in CPDI levels in Bangladesh. Chittagong and Sylhet region respondents have reported a significantly higher level of CPDI than Dhaka. This can be supplemented with the fact that psychological distress levels are influenced by accessibility of local medical resources, effectiveness of the regional public health system, and prevention and control measures taken against the epidemic situation. ${ }^{22}$ Bangladesh has unequal distribution of health care workforce largely concentrated in the urban areas and this is coupled with one of the lowest availability of health care workers in the world, with only 7.4 skilled workers per 10 , 000 population. $^{23}$

\subsection{Limitation of the study}

First, this study was conducted using an observational cross-sectional survey, so our findings are predictive instead of causal. Second, our sample is not nationally representative, as our focus was to identify for policymakers and potential caregivers who in the population might need more help.

\section{Conclusion}

Overall, this paper suggest more than half of the study population in Bangladesh were experiencing psychological distress, with level of distress varies by different symptoms and selected predictors such as region and gender. While there is no clear evidence about the population level prevention, but it leads us to conclude that steps taken now can 
Table 4

Predictors of CPDI through bivariate logistic regression, Bangladesh.

\begin{tabular}{|c|c|c|c|c|c|}
\hline & \multirow[t]{2}{*}{ Odds Ratio } & \multicolumn{3}{|c|}{$95 \%$ C.I. for Odds ratio } & \multirow[b]{2}{*}{ p-value } \\
\hline & & Lower & & & \\
\hline \multirow[t]{2}{*}{ Gender } & Male & Reference & & & \\
\hline & Female & 2.435 & 1.662 & 3.568 & $.000^{* *}$ \\
\hline \multirow[t]{2}{*}{ Religion } & Others & Reference & & & \\
\hline & Islam & 0.861 & 0.463 & 1.600 & .635 \\
\hline \multirow[t]{2}{*}{ Age } & 18-30 year & Reference & & & \\
\hline & $30+$ years & 0.975 & 0.503 & 1.889 & .941 \\
\hline \multirow[t]{2}{*}{ Education } & School & Reference & & & \\
\hline & College & 1.016 & 0.596 & 1.732 & .954 \\
\hline \multirow[t]{3}{*}{ Employment } & Not Employed & Reference & & & \\
\hline & Employed & 1.772 & 0.988 & 3.178 & .055 \\
\hline & Student & 1.260 & 0.767 & 2.070 & .361 \\
\hline \multirow[t]{3}{*}{ Household Income } & $\begin{array}{l}\text { BDT less than } \\
25,000\end{array}$ & Reference & & & \\
\hline & $\begin{array}{l}\text { BDT } 25,000 \text { to } \\
\text { less than } \\
50,000\end{array}$ & 1.048 & 0.656 & 1.674 & .844 \\
\hline & $\begin{array}{l}\text { BDT More than } \\
50,000\end{array}$ & 1.015 & 0.614 & 1.676 & .955 \\
\hline \multirow[t]{4}{*}{ Region } & $\begin{array}{l}\text { Dhaka/ } \\
\text { Mymensing }\end{array}$ & Reference & & & \\
\hline & $\begin{array}{l}\text { Rajshahi/ } \\
\text { Rangpur }\end{array}$ & 0.812 & 0.417 & 1.583 & .541 \\
\hline & Barisal/Khulna & 1.436 & 0.685 & 3.011 & .338 \\
\hline & $\begin{array}{l}\text { Chittagong/ } \\
\text { Sylhet }\end{array}$ & 1.945 & 1.047 & 3.612 & $.035^{*}$ \\
\hline
\end{tabular}

${ }^{* *} \mathrm{p}<0.01, * \mathrm{p}<0.05$

help us proactively prepare for the inevitable increase in mental health conditions and associated sequelae that are the consequences of this pandemic. $^{24}$

\section{Ethical approval}

The study was designed and conducted in accordance with the Helsinki declaration and was approved by the Ethics Committee of Asia Metropolitan University. All participants completed an informed written consent form before starting the survey.

\section{Funding}

The present study is not funded or received grant from any funding agency, commercial entity or not-for-profit organization.

\section{Declaration of competing interest}

The authors have no conflicts of interest to declare.

\section{References}

1 World Health Organization. Coronavirus disease (COVID-19) pandemic. Available from: https://www.who.int/emergencies/diseases/novel-coronavirus-2019?gclid =EAIaIQobChMImer64Ovf6gIVin4rCh1YGwLJEAAYASAAEgLK1_D_BwE ; 2020 Accessed July 22, 2020.

2 World Health Organization. Global Bangladesh on coronavirus disease (COVID-19) 2020. Available from: https://covid19.who.int/region/searo/country/bd; 2020. Accessed July 22, 2020.
3 Yu-Tao Xiang, Yang Yuan, Wen Li, et al. Timely mental health care for the 2019 novel coronavirus outbreak is urgently needed. The Lancet Psychiatry. 2020. https:// doi.org/10.1016/S2215-0366(20)30046-8. PMID: 32032543.

4 Kang Lijun, Li Yi, Hu Shaohua, et al. The mental health of medical workers in Wuhan, China dealing with the 2019 novel coronavirus. The Lancet Psychiatry. 2020. https:// doi.org/10.1016/S2215-0366(20)30047-X PMID: 32035030.

$5 \mathrm{Li} \mathrm{Li}$, Wan Changli, Ding Ru, et al. Mental distress among Liberian medical staff working at the China Ebola Treatment Unit: a cross sectional study. Health Qual Life Outcome. 2015;13(1). https://doi.org/10.1186/s12955-015-0341-2 PMID: 26409446.

6 Lau JTF, Tsui HY, Kim JH, Chan PKS, Griffiths S. Monitoring of perceptions, anticipated behavioral, and psychological responses related to H5N1 influenza. Infection. 2010;38(4):275-283. https://doi.org/10.1007/s15010-010-0034-z PMID: 20582562.

7 Hollifield M, Hewage C, Gunawardena CN, Kodituwakku P, Bopagoda K, Weerarathnege K. Symptoms and coping in Sri Lanka 20-21 months after the 2004 tsunami. Br J Psychiatry. 2008;192(1):39-44. https://doi.org/10.1192/bjp. bp.107.038422 PMID: 18174508 .

8 Huang Junhua, Liu Qunying, Li Jinliang, et al. Post-traumatic stress disorder status in a rescue group after the Wenchuan earthquake relief. Neural.Regeneration.Res. 2013;8 (20):1898-1906. https://doi.org/10.3969/j.issn.1673-5374.2013.20.009 PMID: 25206499.

9 Scheenen ME, Spikman JM, De Koning ME, et al. Patients "at risk" of suffering from persistent complaints after mild traumatic brain injury: the role of coping, mood disorders, and post-traumatic stress. $J$ Neurotrauma. 2017;34(1):31-37. https://doi. org/10.1089/neu.2015.4381 PMID: 27560623.

10 Wang L, Kang C, Yin Z, Su F. Psychological endurance, anxiety, and coping style among journalists engaged in emergency events: evidence from China. Iran J Public Health. 2019;48(1):95-102. PMID: 30847316.

11 Wei-Qing Chen, Tze-Wai Wong, Yu Tak-Sun. Direct and interactive effects of occupational stress and coping on ulcer-like symptoms among Chinese male off-shore oil workers. Am J Ind Med. 2009;52(6):500-508. https://doi.org/10.1002/ ajim.20691 PMID: 19267333.

12 Sliter M, Kale A, Yuan Z. Is humor the best medicine? The buffering effect of coping humor on traumatic stressors in firefighters. J Organ Behav. 2014;35(2):257-272. https://doi.org/10.1002/job.1868.

13 Taylor MR, Agho KE, Stevens GJ, Raphael B. Factors influencing psychological distress during a disease epidemic: data from Australia's first outbreak of equine influenza. BMC Publ Health. 2008;8(1):347. https://doi.org/10.1186/1471-2458-8347 PMID: 18831770.

14 Stallard P, Velleman R, Langsford J, Baldwin S. Coping and psychological distress in children involved in road traffic accidents. 2001;40(2):197-208. PMID: 11446241.

15 Qiu J, Shen B, Zhao M, Wang Z, Xie B, Xu Y. A nationwide survey of psychological distress among Chinese people in the COVID-19 epidemic: implications and policy recommendations. General psychiatry. 2020;33(2).

16 Anwar S, Nasrullah M, Hosen MJ. COVID-19 and Bangladesh: challenges and how to address them. Front.Public Health. 2020;8.

17 Bunnell BE, Davidson TM, Ruggiero KJ. The Peritraumatic Distress Inventory: factor structure and predictive validity in traumatically injured patients admitted through a Level I trauma center. J Anxiety Disord. 2018;55:8-13.

18 AfsharJahanshahi A, MokhtariDinani M, NazarianMadavani A, Li J, Zhang SX. The distress of Iranian adults during the Covid-19 pandemic - more distressed than the Chinese and with different predictors. medRxiv. 2020. https://doi.org/10.1101/ 2020.04.03.20052571.

19 Rathod S, Pinninti N, Irfan M, et al. Mental health service provision in low-and middle-income countries. Health Serv Insights. 2017;10, 1178632917694350.

20 Sareen J, Erickson J, Medved MI, et al. Risk factors for post-injury mental health problems. Depress Anxiety. 2013;30:321-327. https://doi.org/10.1002/da.22077.

21 Women UN. Gender and COVID-19: surveys show that COVID-19 has gendered effects in Asia and the pacific. https://data.unwomen.org/resources/surveys-show-c ovid-19-has-gendered-effects-asia-and-pacific; 2020.

22 Lowe SR, Sampson L, Gruebner O, et al. Psychological resilience after Hurricane sandy: the influence of individual- and community- level factors on mental health after a large- scale natural disaster. PloS One. 2015;10, e0125761.

23 World Health Organization. The global health observatory data repository. Available: https://apps.who.int/gho/data/node.main.HWFGRP_0020; 2020. Accessed June 13, 2020.

24 Galea S, Merchant RM, Lurie N. The mental health consequences of COVID-19 and physical distancing: the need for prevention and early intervention. JAMA internal medicine. 2020 